Cuadernos de Relaciones Laborales

ISSN: 1131-8635

https://dx.doi.org/10.5209/crla.66038

\title{
Retos y propuestas para la regulación del trabajo en los procesos productivos de las plataformas digitales
}

\author{
Laurentino J. Dueñas Herrero ${ }^{1}$
}

Recibido: 20 de junio de 2019 / Aceptado: 25 de septiembre de 2019

Resumen. La OIT, la UE, los Estados y los interlocutores sociales pueden normar el ámbito económico desregularizado o con lagunas en la regulación de la digitalización y de la economía de plataformas. No hay estrictamente un lugar de trabajo, pero hay personas que producen en el ámbito de una organización que coloca su producto en el mercado. Realmente ¿el aleph de la platform economy está tan escondido y tan bien camuflado que se hace inaccesible para las leyes existentes y para las que están por llegar? Seguramente mediante una Directiva negociada se pueden regular los derechos y las obligaciones de los trabajadores en la economía de plataformas.

Palabras clave: economía de plataformas; procesos reguladores; interlocutores sociales; diálogo social.

\section{[en] Challenges and proposals for the regulation of work in the productive processes of the digital platforms}

\begin{abstract}
ILO, EU, States and social partners can establish rules for an economic sphere that is deregulated or has significant gaps in regulation: digitalization and the platform economy. There is no strictly defined workplace, but there are people who produce within the scope of an organization that places its product on the market. Is the aleph of the collaborative economy really so well hidden and so well camouflaged that it becomes inaccessible to existing laws and to laws that are to come? Surely, through a negotiated Directive, the rights and obligations of workers in platform economy can be regulated.
\end{abstract}

Keywords: platform economy; normative processes; social partners; social dialogue.

Sumario. 1. Contextualización: el Derecho del trabajo ante la irrupción de la economía de plataformas. 2. Objeto de regulación: el trabajo y sus condiciones. 3. Retos del nuevo marco normativo. 3.1. Escenario: la trastienda de las plataformas digitales. 3.2. Los instrumentos reguladores y los espacios de producción normativa. 4. Propuesta: una gobernanza reguladora participada por el diálogo social. 5. Bibliografía.

Cómo citar: Dueñas Herrero, L. J. (2019). Retos y propuestas para la regulación del trabajo en los procesos productivos de las plataformas digitales, Cuadernos de Relaciones Laborales, 37(2), 275-292.

\section{Contextualización: el Derecho del trabajo ante la irrupción de la economía de plataformas}

El planteamiento inicial toma en consideración la necesidad de superar la inseguridad jurídica creada por los problemas de articulación jurídica que están generando

1 Profesor titular de Derecho del Trabajo y de la Seguridad Social

Universidad de Valladolid

E-mail: lauren@emp.uva.es 
dos fenómenos productivos que van de la mano: globalización y digitalización. Y la hipótesis de partida no se separa de otros estudios en este sentido: la existencia de una necesidad objetiva de adaptación del Derecho del trabajo para encauzar adecuadamente el desarrollo de un nuevo modelo económico, que exige intervenciones de actores con capacidad reguladora en el mercado de trabajo (Rodríguez-Piñero Royo, 2017: 128). En primer lugar, son convenientes algunas precisiones. No debe confundirse la digitalización de la economía, que afecta a todos los sectores productivos, con la aparición de empresas que actúan en el ámbito de las plataformas digitales, que crean un tipo de empleo con especial deriva hacia el trabajo autónomo, pero en un espacio que no es ajeno por completo al trabajador subordinado (Cruz Villalón, 2018: 17-18). Estas nuevas formas de trabajo tienden a caracterizarse por una terminología ambigua: economía participativa, nube humana, fuerza de trabajo a demanda, trabajo digital, y el crowdsourcing, que es entendido como trabajo remunerado organizado a través del trabajo en línea (González-Posada Martínez, 2018: 22). Y precisamente, para evitar equívocos con denominaciones como "economía colaborativa" o "sharing economy", llamar a las cosas por su nombre es hablar de "platform economy" o economía de plataformas, de forma que nos evitemos calificaciones que puedan tener un impacto positivo o negativo en el ideario colectivo sobre lo que hacen o dejan de hacer estas empresas on-line (Rodríguez Fernández, 2019: 60).

Dicho lo anterior, también conviene matizar que la inmediatez del relato que nos ocupa no es tan disruptivo como se manifiesta por algunos operadores jurídicos, pues permanece en el tiempo, y ya se dijo en el siglo pasado que los perniciosos cambios que la globalización estaba generando -muy parejos a los ocasionados por la digitalización-sobre la articulación tradicional de las fuentes reguladoras de las relaciones de trabajo, se constatan en la Unión Europea y en sus Estados miembros de forma parecida: se procede a un desmantelamiento de los sistemas de garantías, principalmente a través de la reducción de las capacidades de acción de los sujetos colectivos, la debilitación de la norma imperativa estatal y la recuperación de amplios espacios normativos a la unilateralidad de las decisiones empresariales (Baylos Grau, 1999: 24). En otros términos, actualmente hay un replanteamiento del intervencionismo público en el ámbito de las relaciones laborales porque se ha ido produciendo un retroceso o repliegue del Estado en la regulación material de las relaciones laborales ante, por ejemplo, la actuación de poderes supranacionales o privados que imponen la "gobernanza económica global" (Moreno Vida, 2019: 258). El impacto de la digitalización del trabajo plantea un problema de fuentes del Derecho, en otros términos, de regulación de las condiciones de trabajo. Así, se puso de manifiesto que el caos de la digitalización iba camino de convertirse en un "factor de incertidumbre" sobre el concepto mismo de ley, a la vez que provocaría un progresivo deterioro y una deformación técnica de las formas legales en el conjunto de cada uno de los ordenamientos internos (Mercader Uguina, 2003: 670-671). La ley tiende cada vez más a separarse de la fuerza "inderogable" que antes le caracterizaba produciendo una "remercantilización" del contenido de los derechos sociales, que se contractualizan; la autonomía colectiva ocupa espacios que antes estaban reservados a la norma estatal, pero la fortaleza sindical disminuye por los cambios en el modelo de negociación colectiva; y, este replanteamiento de fuentes se ha visto acompañado de una mayor apertura hacia la individualización de las relaciones laborales (Moreno Vida, 2019: 258-259). Et hoc est quod factum est, porque lo cierto es que esta nueva realidad busca continuamente situarse en espacios de "desregulación", a fin de abaratar costes 
y eludir responsabilidades con respecto a quienes prestan servicios para las plataformas, por ello el Derecho del trabajo debe encontrar categorías jurídicas y respuestas adecuadas para evitar la precariedad derivada de un trabajo totalmente individualizado, desestructurado y desprotegido, pues en general el déficit de intervención legislativa en este campo es la nota predominante (Ramos Quintana, 2018: 10-11).

Y una de las preguntas claves qué debemos hacer de cara a crear un Derecho del trabajo con futuro es: "¿podría aceptar el modelo capitalista un sistema en el que la regla fuera el trabajo autónomo? (Mercader Uguina, 2017: 49). Pero la formulación se puede hacer empleando otros erotemas: ¿acaso este "modelo económico tecnológicamente revolucionario" no se parece al trabajo "fordista", al de "siempre", pero en "formato digital", que requiere de la norma laboral clásica para evitar una neo o re-mercantilización del trabajo y la defraudación de aquélla? / ¿Qué diferencia sustancial hay con la externalización y micro-pagos de figuras profesionales típicas de la "era analógica", como son las "camareras de piso"? (Molina Navarrete, 2017: 417-418). O bien, podemos encontrarnos con cuestiones claramente intencionadas que persiguen crear una narrativa y enviar un mensaje de ruptura con lo establecido: ¿cómo vamos a someter las plataformas a reglas que ya existen y que estaban pensadas para las situaciones pasadas? ¿cómo vamos a analizar la relación entre la plataforma y un "partner" con los cánones que hemos utilizado siempre para la relación de trabajo si estamos en un escenario completamente nuevo? Son preguntas que, como esta última, esconden y persiguen un mensaje final: los cánones laboralistas, las reglas de siempre, subordinación y ajenidad, "ya no sirven" porque ahora los partners son contratantes enteramente autónomos y libres (Rodríguez Fernández, 2017: 106). Todas estas cuestiones van por los mismos derroteros y nos llevan a una sola: ¿es necesario exfoliar el tradicional Derecho del trabajo? La respuesta puede ser afirmativa, porque los derechos no se limitan a un "concepto de relación de trabajo que difícilmente se adapta a los nuevos criterios y formas de protección de la actividad económica", o negativa, porque lo anterior no puede conllevar "desprotección y nuevas formas de vulnerabilidad” (Vega Ruiz, 2019: 92). ¿Realmente estamos hablando de refundar y modernizar el Derecho del Trabajo? A estos interrogantes se les puede dar una respuesta neoliberal que no parte de la garantía multinivel de los derechos fundamentales, pero cabe otro tipo de respuesta, que en el constitucionalismo con Estado Social de Derecho no puede ser otra que la de garantizar la efectividad de los derechos sociales fundamentales (Monereo Pérez, 2019: 223).

El trabajo en los procesos productivos digitales abre un nuevo campo para las relaciones jurídicas y los emergentes negocios disruptivos se están desarrollando en unas condiciones laborales tan novedosas que acaban convirtiéndose en los presupuestos habilitantes para su propia regulación. La permeabilidad del mercado de trabajo a los avances tecnológicos plantea importantes desafíos jurídicos. Aunque en España estamos en una fase de reacción incipiente, la rápida progresión tecnológica contrasta con un marco jurídico que sigue anclado en lo clásico (San Martín Mazzucconi, 2017: 302). El factor trabajo asiste al desmembramiento de la firma industrial y a la laminación de la empresa fordista" (Alemán Páez, 2017: 5). La digitalización del conjunto de la economía impacta en el trabajo de la industria y de los servicios, y dentro de estos últimos tanto en los que cabría denominar tradicionales como en los llamados "negocios disruptivos".

En este ensayo trataré sobre la conveniente intervención reguladora ante la plétora de trabajos profesionales existentes en los procesos productivos de platafor- 
mas, ya que estas personas requieren de una red básica de derechos laborales y de protección social. Y mientras llega la ley $-\mathrm{o}$ precisamente porque no parece llegar ni a nivel nacional ni transnacional- es imprescindible una protección inmediata de los derechos de los trabajadores que puede plasmarse en distintos pactos, donde el diálogo social y la negociación colectiva son el medio de protección más eficaz ante las nuevas realidades de economía de plataformas. Además, en las nuevas formas emergentes de trabajo en la era de la digitalización, hay un discurso en el que se sostiene la necesidad de un trabajo flexible, atípico, parcial o a distancia como únicas formas de empleo en el período de recuperación económica tras la crisis, que se solapa con el fortalecimiento de la idea de la descolectivización y de la negación de una identidad colectiva de ser representada por un sujeto sindical, dicho en otros términos, hay un "borrado de la dimensión colectiva regulativa en un panorama en donde la individualización y la negación del conflicto constituyen los nuevos principios rectores" (Baylos Grau, 2019: 312 y 319-321). Pero hay que reaccionar ante los intentos del destierro de ideas-fuerza como es la transferencia del riesgo empresarial a las condiciones de trabajo y de vida de los trabajadores a través de la exclusiva consideración de éstas como un mero factor de producción con el que asegurar un nivel de beneficios (Trillo Párraga, 2017: 72).

\section{Objeto de regulación: el trabajo y sus condiciones}

La digitalización de la economía abre un nuevo campo para las relaciones jurídicas y los negocios disruptivos se están desarrollando en unas condiciones de trabajo tan novedosas que pueden convertirse en los presupuestos habilitantes de una futura legislación europea. Si bien, se está generando un nuevo escenario de litigiosidad, donde las partes en conflicto continúan siendo empresario y trabajador, pero la controversia ya no suscita un problema de legalidad o de contractualidad sino, y ello es bien diferente, de colisión entre dos categorías de derechos fundamentales: los de la persona o de la personalidad y la libertad de empresa (el nuevo escenario no otra cosa pone en conflicto que auténticos derechos constitucionales). Como bien se ha indicado, el peligro reside en que el ejercicio de esos derechos de la persona del trabajador pueden quedar en una situación de penumbra jurídica por la anomia normativa generalizada (por las normas típicamente laborales y por la negociación colectiva) en la que han de desenvolverse los derechos de la persona del trabajador, "lo que pone en manos de los jueces la delicada tarea de adecuar los derechos fundamentales de la persona del trabajador a la normativa infraconstitucional sobre el contrato de trabajo" (Valdés Dal-Ré, 2017: 10-11). Y qué no decir de los derechos de representación del personal autónomo o por cuenta ajena que presta sus servicios en las plataformas digitales intermediarias entre ellos y los receptores de su producción. Como se analizará más adelante, hasta ahora está siendo decisivo el papel del regulador judicial para delimitar las fronteras de la laboralidad y la no laboralidad (muy pegado a relatos de elaboración de "indicios" de la ajenidad y de la dependencia), pero previamente es decisivo el papel del legislador, incluso promocional, que no puede permanecer impasible ante las nuevas experiencias y formas de trabajar que conforman la realidad de nuestra actual sociedad digitalizada y el actual "sector social" de estos trabajadores. Es necesario regular "con claridad y seguridad las consecuencias concretas de todo orden (de seguridad social y fiscales, desde luego), de 
su defraudación y de las consiguientes declaraciones judiciales de laboralidad frente a simulaciones contractuales" (Casas Baamonde, 2015: 718).

El TJUE ha optado tradicionalmente por una interpretación amplia de condiciones de trabajo (que incluye desde la retribución hasta el despido o las pensiones) y para determinar si una medida está incluida en las condiciones de trabajo ha tomado como criterio decisivo el del empleo, es decir, la relación de trabajo entre un trabajador y su empresario. Se trata de un concepto con pocas exclusiones, prácticamente solo las condiciones relativas a las pensiones que se derivan de un régimen legal de seguridad social. Aparecen nuevas condiciones que deben ser objeto de regulación, pero no desaparecen las ya existentes en el trabajo industrial y éstas deben regularse también en el campo de la economía digital. Ahora bien, es cierto que se precisa una regulación o autorregulación para clarificar los derechos sociales de estos trabajadores, pero esto también ha de ser posible en el ámbito nacional, pues no se puede pedir que a nivel europeo se reglamente el derecho a la negociación colectiva, o los derechos de asociación, sindicación o huelga para estos trabajadores, como tampoco para los trabajadores típicos, porque es legislación laboral no permitida a la Unión Europea (Castellano Burguillo, 2017: 277). Frente a esto nos encontramos con el silencio legal que es, hasta cierto punto comprensible, pues no es fácil dar respuesta a conflictos vinculados a herramientas tecnológicas en permanente evolución, porque no es fácil la solución legal rígida o más dinámica, ya que las disposiciones normativas tienen vocación de permanencia y deben ofrecer seguridad jurídica. En suma, la ausencia de un marco legal suficiente determina que sean los tribunales, nacionales y supranacionales, los que están dando respuesta a estos conflictos laborales derivados del uso de las tecnologías innovadoras en las empresas (San Martín Mazzucconi, 2017: 301).

Si apostamos por la intervención de la legislación laboral, será necesario identificar los escenarios donde la economía colaborativa actúa a través de una plataforma como sistema de gestión, las actividades mercantiles de intermediación de las plataformas entre los prestadores de servicios y los usuarios/receptores finales de estos. Hay que analizar por qué formalmente dichos prestadores aparecen como autónomos en sus relaciones con las plataformas y como ajenos en su conexión con el mercado. ¿Cuándo terminará la función meramente observadora de la legislación laboral? ¿Dónde debe intervenir el legislador, cómo y con qué alcance? La primera cuestión a resolver es determinar la naturaleza de la relación que une a la plataforma con los prestadores del servicio y después también se puede reclamar la existencia de mecanismos de representación del personal que pudieran protagonizar acciones de negociación y de gestión del conflicto, aparte de otras relevantes condiciones de trabajo (Garrido Pérez, 2017: 212-213).

Sin duda, deviene necesario abordar el debate de la necesidad o conveniencia de adaptar o no la regulación laboral al trabajo en la era digital. Por ejemplo, un interrogante que sigue planeando es si tras enfrentarse al análisis de esta zona gris, ¿se adecúa la actual regulación laboral a las características propias de esta forma de prestación de servicios? Existen, esencialmente, dos posiciones: (i) una inmovilista $\mathrm{y}$, por tanto, consistente en prohibir formas de prestación de servicios que permitan tanta flexibilidad, por ejemplo, en la determinación de la jornada; (ii) otra reformista que, como apuntan algunos autores, consiste en la introducción de una regulación específica que permita atender tanto a las particularidades de estas empresas tecnológicas como a proteger los intereses de los trabajadores. Hay toda una labor previa 
de definición del trabajo en plataforma, y tras ello queda igualmente una labor de adaptación de conceptos e instituciones del Derecho del trabajo a este nuevo escenario, como es el de centro de trabajo (Garrido Pérez, 2017: 232). Quizás, la otra consecuencia de la negación del trabajo y su función sociopolítica en estas plataformas virtuales es la banalización en última instancia de la condición de trabajador por cuenta ajena, así como del sujeto colectivo de representación de sus intereses; sin embargo, existen experiencias sindicales al respecto y han proliferado organizaciones corporativas en este contexto (Trillo Párraga, 2016: 78-80).

En realidad, no se trata de otra cosa que de exigir -ante cualquier manifestación de trabajo atípico o no atípico- la garantía de un trabajo decente y de una protección mínima. Tal punto de partida queda perfectamente definido en el Informe que la OIT publicó en noviembre de 2016: "Empleo no normalizado o atípico en todo el mundo: entender los desafíos, dar forma a las perspectivas", donde se identifican hasta siete áreas de inseguridad comunes a las diversas formas de trabajo atípico (Serrano Olivares, 2017: 31-33). En otras palabras, hay que conceder a estos trabajadores unas mínimas garantías laborales y que su desarrollo tenga lugar en unas dignas condiciones. En concreto, tomando como referencia los documentos de la Comisión Europea, sus propuestas promueven crear una Estructura de Apoyo Justa y Digna, basada en una serie de pilares que permitirían un desarrollo adecuado de las plataformas: establecimiento de un salario mínimo, junto con un máximo número de horas de trabajo al día; un mínimo de protección social y de aseguramiento de la salud; alguna forma de aseguramiento por daños a terceros; medidas de protección de la salud y la seguridad; el aseguramiento de la protección de la intimidad del trabajador; y que la clasificación algorítmica automática y las calificaciones reputacionales no produzcan discriminación por razón de género, origen étnico, raza y edad (Rodríguez-Piñero Royo, 2017: 207-208).

El objeto que requiere ser regulado parte de una concepción individualista tanto de la empresa en sí como del trabajo, no sólo por la deslocalización física sino por la determinación de las condiciones de trabajo y la evaluación individual de la productividad de cada trabajador (incluso, en el caso de las plataformas son los clientes los que fijan las condiciones de forma indirecta). En pocas palabras, también el concepto de empresa tradicional desde la perspectiva jurídico-laboral, parece haber desaparecido como modelo (Vega Ruiz, 2019: 90). El efecto sinérgico a resultas de la acumulación aplicativa de tres factores: globalización, procesos tecnológicos y transformaciones organizativas, presiona con intensidad hacia la reducción del costo del trabajo y desemboca en la aparición de un fenómeno hasta el presente desconocido, como es el de los denominados "trabajadores pobres" (Cruz Villalón, 2017: 18). A mayor abundamiento, ante el desarrollo de nuevas formas de empleo a consecuencia del consumo colaborativo, de la digitalización y de la automatización, se producen, entre otros muchos, dos efectos, comprobados según la OIT y el Parlamento Europeo: 1) se desdibujan los límites entre el empleo por cuenta ajena y el autónomo; y 2) se favorece el incremento de empleos atípicos con proyección negativa en el difícil equilibrio entre la vida privada y laboral, lo que tiene un efecto perjudicial sobre las mujeres (Casas Baamonde, 2017: 872). Y la consecuencia de cierre es que esas amablemente llamadas "formas atípicas de trabajo" devalúan las condiciones de empleo, incrementan el trabajo autónomo ficticio y/o precario, y el falso trabajo a tiempo parcial, provocan segregación y pobreza laboriosa, y aniquilan el vínculo de representación colectiva y sindical (Martínez Moreno, 2019: 282). 


\section{Retos del nuevo marco normativo}

La entrada del consumidor en el ciclo de producción y la flexibilidad de su desarro1lo, paralelamente a la sustitución del trabajo manual por la automatización, ya no hacen necesaria la organización estática del trabajo. Surge así el reto de un nuevo marco regulador del trabajo que se coloque en la misma línea en que se conduce la Industria 4.0 (González-Posada Martínez, 2018: 25 y 28). Es importante subrayar el trasfondo político-ideológico y economicista subyacente a las decisiones de política del Derecho, que tratan de flexibilizar las relaciones de trabajo, garantizar un correcto funcionamiento del orden público económico y expandir las libertades económicas de los empresarios (Monereo Pérez, 2017: 17). Una vez más se vuelve a anunciar el fin del trabajo dependiente por causa de la digitalización o la necesidad de inventar nuevos estatutos jurídicos para regularizar el trabajo propio de la era digital, lo cual es un tanto precipitado o claramente tendencioso, porque en muchas ocasiones pueden rastrearse claros síntomas de subordinación, aunque la plataforma que ejerce el poder de control y también el de disciplina carezca de subordinación (Rodríguez Fernández, 2017: 113); y, aunque ya se esté planteando la revisión del concepto mismo de trabajador -en aras a sustituir la subordinación por la dependencia económica- o a reclamar la creación de una nueva categoría jurídica para los empleados digitales, en el fondo esto forma parte del "ADN mismo del Derecho del Trabajo" porque no estamos ante otra cosa que "las zonas grises de la subordinación" (Conferencia Nacional Tripartita, 2017: 67-68). Todas estas consideraciones se vinculan directamente con la gobernanza del trabajo. Y aquí, la gobernanza nacional, a través de las instituciones del mercado laboral «tradicionales», continúa siendo fundamental.

\subsection{Escenario: la trastienda de las plataformas digitales}

Nos encontramos ante un establecimiento etéreo que deja entrever en la trastienda la existencia de una organización empresarial. No hay estrictamente un lugar de trabajo, pero hay personas que producen en el ámbito de una organización que coloca su producto en el mercado. Por tanto, la clásica tríada se repite: empresario intermediario, trabajador prestador del servicio y cliente consumidor o usuario; no otro es el modelo de negocio que se plantea en las plataformas colaborativas (Comunicación de la Comisión Europea "Una agenda europea para la economía colaborativa", COM (2016) 356 final, Bruselas, 2-06-2016, pp. 60-61). Como se defiende en este trabajo, si se acepta que al sector del "Derecho digital" le son de aplicación las regulaciones generales, la discusión se traslada a otro plano, si deben o no adaptarse éstas para acomodarlas a sus particularidades; o si es necesario elaborar otra regulación ad hoc (Rodríguez-Piñero Royo, 2017: 201). Es más, y con el objetivo de evitar que las empresas con ánimo de lucro utilicen de forma abusiva las plataformas de empleo y trabajo y, al mismo tiempo, realicen prácticas ilegales, se impone la necesidad de una regulación, respecto de la cual podemos discutir su forma y contenido, pero no la necesidad de su existencia (Castellano Burguillo, 2017: 271).

Es preciso actuar contra el empleo precario y contra el debilitamiento de la negociación colectiva y de la cobertura de los convenios colectivos en la economía de plataformas, pero la garantía y defensa de los derechos de los trabajadores en la economía de plataformas no puede dejarse exclusivamente a la ley, pues la rapidez de los cambios hace que la negociación colectiva se convierta en imprescindible. 
Además de la ley, el medio idóneo para la protección de las nuevas realidades tecnológicas y digitales en las relaciones laborales es la negociación colectiva, a través de acuerdos, convenios y pactos colectivos. Por ello, se debe salvaguardar y reforzar la función de los sindicatos y las organizaciones empresariales en estas nuevas empresas disruptivas, lo que no es fácil ante un discurso que garantiza la elusión de la fuerza vinculante del convenio colectivo en el ámbito de la empresa descentralizada y atomizada, en la que además de la desaparición de la noción de centro de trabajo, impide anclar en él los mecanismos de representación colectiva que la norma prevé para el conjunto de los trabajadores y que mide la implantación de los sindicatos a través de la audiencia sindical" (Baylos Grau, 2019: 320).

Aunque no existe un consenso total sobre la exigencia de una intervención en el sector, en este ensayo no se contempla la posibilidad de una ausencia de regulación ni la "utopía del mercado autorregulado", sino que se opta por la "opción reguladora", donde se precisa la definición de los espacios que deben corresponder a la ley, a los convenios, a la autorregulación por las plataformas y a los acuerdos individuales con éstas y sus clientes (Rodríguez-Piñero Royo, 2017: 129). Concretando todavía más, las alternativas reguladoras pueden clasificarse en las siguientes necesidades delimitadoras: 1. Determinar quién es empresario desde un punto de vista funcional a efectos de asumir responsabilidades; 2. Ampliar el concepto clásico de trabajador dependiente para incluir en él a este nuevo colectivo; 3 . Crear una categoría intermedia entre trabajador y autónomo, como la del autónomo económicamente dependiente, que ya existe en el ordenamiento español; y 4. Aprobar una regulación específica para todos estos trabajadores con un catálogo común de derechos laborales (Mella Méndez, 2019: 92). Cualquier regulación específica debe caracterizarse por los siguientes rasgos: carácter internacional y común (OIT y UE); carácter protector mínimo (que puede ser mejorado a través de la normativa interna de los Estados miembros y por interlocutores sociales) y ámbito subjetivo omnicomprensivo de todos los trabajos en plataformas (mediante la inclusión por la Directiva de un concepto amplio de trabajador). Por todas estas razones se propone la aprobación de una Directiva para regular unas condiciones de trabajo mínimas aplicables a todos los prestadores de servicios de las plataformas que incluya un concepto amplio de trabajador (Mella Méndez, 2019: 92-95). Por ello, lo recomendable es legislar en los países de la UE de manera homogénea, a través de una Directiva Marco que determine la actuación comunitaria en el ámbito de la política en materia de plataformas digitales, dejando a las autoridades internas competentes la elección de la forma y los medios adecuados a tal fin, para regular sobre: el estatus jurídico de los prestatarios de servicios de las plataformas digitales, la prevención de riesgos laborales, la forma de computar trabajadores, la garantía del salario mínimo del país donde prestan los servicios, el régimen de las penalizaciones y la posibilidad de trabajar a la vez para varias plataformas digitales (Cuadros Garrido, 2019: 161-162).

En definitiva, hay toda una labor previa de definición del trabajo en plataforma, y tras ello resta igualmente un proceso de adaptación de conceptos e instituciones de Derecho laboral a este nuevo escenario, como es el de centro de trabajo, predeterminar unos mínimos y máximos de tiempo de trabajo, el respeto al suelo mínimo de contratación y remuneración, al margen de otras garantías en sede de protección social, la explosión de "riesgos psicosociales informacionalizados", lo que para algunos autores se puede hacer regulando este trabajo como una relación laboral especial de trabajadores que prestan servicios para plataformas virtuales (Todolí Signes, 2017: 
71-75). Este régimen especial debe desarrollar los siguientes aspectos de la Directiva marco: la negociación colectiva, la sindicación, las especialidades preventivas, la garantía de un salario mínimo o el pluriempleo, especialidades que deberían ser disciplinadas fundamentalmente por normas reglamentarias dada la mayor rigidez de la ley. En definitiva, se trata de crear normas de Derecho necesario, que modifiquen la autorregulación abusiva que hoy en día realizan las compañías de plataformas (Cuadros Garrido, 2019: 163). A esta línea alternativa de actuación legislativa que conlleva la regulación de un estatuto jurídico propio del trabajador digital, algunos autores la han llamado "Tercera Vía" y que defienden es la seguida por la Unión Europea, tal y como se refleja en diversas iniciativas legislativas: a) propuesta de Directiva del Parlamento Europeo y del Consejo relativa a unas condiciones laborales transparentes y previsibles en la UE, de 21 de diciembre de 2017, que propone garantizar un nivel de protección universal básico y da cabida a un catálogo de derechos para todos los trabajadores, asalariados o autónomos; b) Dictamen del Comité de las Regiones Europeo: "La dimensión local y regional de la economía colaborativa" (2016), donde se admite que los trabajadores de la economía colaborativa necesitan garantías sociales y económicas; c) el Parlamento Europeo en la Resolución de 15 de junio de 2017, sobre una "Agenda Europea para la economía colaborativa", donde se afirma que se debe dar protección social a todos los trabajadores de la economía colaborativa, con independencia de su estatus de asalariado o de trabajador autónomo; la Confederación Europea de Sindicatos, ha elaborado diversas propuestas, entre ellas a la Comisión Europea, 16 de julio de 2018, precedida por el Documento Frankfurt (6 de diciembre de 2016), consistente en la elaboración de un catálogo de derechos mínimos aplicables a los trabajadores de las plataformas en línea, admitiendo también la inclusión de este catálogo para "autoempleados independientes"; y en la misma línea la Propuesta de Recomendación del Consejo Europeo, de 13 de marzo de 2018, relativa al acceso a la protección social para los trabajadores por cuenta ajena y por cuenta propia que realizan trabajos no convencionales a través de plataformas digitales (Rojas Rosco, 2018: 133-134).

Desde la Unión Europea se ha instado a normar este sector desregularizado o con lagunas en la regulación, pidiendo las directrices necesarias a la Comisión Europea, así como a los Estados miembros y a los interlocutores sociales para que pongan en práctica las recomendaciones dirigidas desde el Parlamento Europeo para que se regulen las plataformas colaborativas, de cara a garantizar mayor seguridad jurídica respecto de los modelos de empresa colaborativa y una protección suficiente a los derechos de los trabajadores que prestan servicios a través de plataformas virtuales (Resolución del Parlamento Europeo, de 15 de junio de 2017 UE, sobre una Agenda Europea para la economía colaborativa.). Como se ha dicho, nos parece pacífica la consideración de que estos nuevos escenarios productivos no pueden operar en un marco de absoluta libertad o de alegalidad, y, consiguientemente, resulta exigible una intervención reguladora, pero la dificultad estriba en delimitar hasta dónde llegar o cómo ordenar estos ámbitos para conseguir un necesario equilibrio entre los intereses y las expectativas en juego (Garrido Pérez, 2017: 210-213). Por tanto, el problema es definir qué es trabajo y cuál es la regulación que se necesita. No cabe duda que la ordenación es necesaria, pero ¿cuál es el tipo de protección y el ámbito protegible? ¿Quiénes deben hoy ser considerados trabajadores y cuáles son sus necesidades? (Vega Ruiz, 2019: 88). Aunque puede que lo único necesario en realidad, sea romper con esa especie de "determinismo tecnológico" que nos invade, porque 
es probable que muchas de las definiciones e instituciones laborales que hemos venido utilizando en el ámbito laboral puedan seguir siendo útiles con la oportuna calibración (Rodríguez Fernández, 2017: 107).

Como se ha mantenido hasta aquí, si damos por resuelto el test de laboralidad de los trabajos en los procesos productivos de plataformas (por cuenta ajena o por cuenta propia), las preguntas borbotean en torno a cuál es la mejor forma de garantizar los derechos de los trabajadores para evitar la precarización. En definitiva, es preciso el planteamiento sucesivo de algunas cuestiones para concluir cuál es el futuro del trabajo que queremos. Desde luego, el legislador puede seguir utilizando los parámetros clásicos tuitivos del Derecho del trabajo dirigidos a garantizar los derechos de los trabajadores sometidos a una precarización como consecuencia de la digitalización laboral. Quiero decir que en todos los países, subordinación y ajenidad son criterios con fuerza delimitadora suficiente de la figura jurídica del trabajador por cuenta ajena. El concepto de trabajador propio del Derecho de la Unión es una noción esencialmente construida a través del método de casos, tiene una vocación extensiva y el TJUE ha señalado que, más allá de las diferencias y variantes nacionales, resulta preciso otorgar un sentido o alcance comunitario y propio a la noción de trabajador, para que la normativa sobre libre circulación no pierda su razón de ser (Martínez Moreno, 2018: 189-190). El problema reside no tanto en regular un concepto amplio de trabajador, sino en delimitar unos derechos mínimos para cualquier persona trabajadora, con independencia de su estatuto jurídico. Así, la OIT aclamó cuatro derechos fundamentales indisponibles: la libertad sindical y la negociación colectiva, la erradicación del trabajo infantil, la no discriminación y la abolición del trabajo forzoso (Declaración de Derechos fundamentales en el trabajo de 1998). Además, a falta del concepto de trabajador, ha establecido los derechos necesarios aplicables a las personas trabajadoras. En el informe de la Comisión sobre el futuro del trabajo marca como condiciones de trabajo básicas: un salario vital adecuado, la limitación de las horas de trabajo y mayor seguridad e higiene en los lugares de trabajo. Se trata de una Garantía Laboral Universal, mejorable a través de la legislación y los convenios colectivos. Este listado puede ser discutible a nivel nacional, por cuanto la Garantía no incluye, por ejemplo, temas como la protección social y el derecho de aprendizaje, que son considerados como recomendaciones necesarias, pero en apartados diferentes (Vega Ruiz, 2019: 98). De cualquier modo, el concepto de trabajador está sometido a fuertes tensiones con la economía de plataformas, el problema se plantea en todos los países y ha obtenido respuestas judiciales no siempre coincidentes, por ello, sería de interés que, al menos en la Unión Europea, se tomara la iniciativa de incorporar un concepto propio de trabajador (García-Perrote Escartín, 2019: 212).

Ahora bien, resulta necesario ampliar el conjunto de estándares mínimos a nivel internacional que permitan avanzar hacia el progreso social. La Declaración de Naciones Unidas sobre la Agenda 2030 sobre Trabajo Decente y Desarrollo Sostenible insta a los Estados a que se abstengan de promulgar y aplicar unilateralmente medidas económicas, financieras o comerciales que no sean compatibles con el derecho internacional y la Carta de las Naciones Unidas. Es preciso establecer un suelo homogeneizador de los estándares de trabajo -como los principios fundamentales de la OIT y los derechos reconocidos en los instrumentos de Naciones Unidas dirigidos a salvaguardar los derechos humanos- que deben respetarse en cualquier lugar y por todas las empresas que se desenvuelvan en una dimensión transnacional (Fita 
Ortega y Nahas, 2019: 1028-1029). Lo cierto es que en cualquiera de las alternativas reguladoras mencionadas, por ejemplo, la revisión de los conceptos de trabajador y de empleador, deben ser afrontadas en un doble plano analítico, ya que no basta con contrastar las insuficiencias de nuestro ordenamiento jurídico frente a la complejidad de esta nueva realidad organizativa, sino que, además, es preciso tener en cuenta la dimensión transnacional de la misma en el marco de una economía cada vez más globalizada (Correa Carrasco, 2019: 39).

\subsection{Los instrumentos reguladores y los espacios de producción normativa}

Es necesario un derecho más equilibrado y armonizado del trabajo en el marco de los procesos productivos de plataformas. La economía digital sombrea en exceso la realidad e intenta dejar totalmente en la penumbra la relación laboral existente. El objetivo de una sólida regulación de este fenómeno contribuirá a eliminar el riesgo de incumplimientos empresariales. Los cambios del mercado, de la técnica o del contexto económico, parecen demandar también una remodelación de la propia estructura u organización de la empresa. Cualquier regulación de estas nuevas formas de producción pasa por la revisión de los conceptos de empleador y de trabajador, lo que requiere encontrar puntos de equilibrio entre la libertad de empresa, que ampararía la facultad de dotarse de las estructuras organizativas que aporten eficiencia y competitividad a la gestión empresarial, y la protección de los derechos de los trabajadores (Correa Carrasco, 2019: 37). Si bien, la caracterización de la economía de plataformas incorpora algunos signos que evidencian una voluntad de escapar a los límites del Derecho del trabajo. El legislador no puede estar ausente, sino que debe ofrecer una respuesta legal desde una posición garantista con la posición del trabajador, y mientras no llega la reacción del legislador, la regulación actual ofrece argumentos suficientes para defender ante los tribunales los derechos de los trabajadores bajo el manto de la relación laboral por cuenta ajena (García Quiñones, 2018: 141-142).

La intervención legislativa se requiere porque la globalización y la digitalización de la economía conforman un contexto económico y una realidad que desembocan en un aumento de la precariedad laboral, ya que utilizan sus fórmulas organizativas como cauces para la obtención de ventajas competitivas sobre la base de la reducción de costes laborales (Correa Carrasco, 2019: 37). No hay duda de que, a nivel institucional europeo, el surgimiento de la economía colaborativa ha levantado gran interés y se ha producido un polémico debate sobre estos procesos productivos, con posicionamientos críticos respecto a las empresas dedicadas al trabajo a través de plataformas virtuales (Del Rey Guanter [dir.], 2019: 129). La globalización, la digitalización y la robotización provocan notables dificultades en el mantenimiento del modelo prevalente, hasta hace poco tiempo, de centralidad de la gobernanza de las relaciones laborales, donde existía un fuerte protagonismo de los Gobiernos nacionales, porque ahora las reglas económicas que condicionan la gestión de las relaciones laborales se fijan a nivel supranacional, de modo que se convierten en un decisivo condicionante para la capacidad de determinación del marco jurídico o institucional por parte de los diferentes Gobiernos nacionales (Cruz Villalón, 2017: 15). La realidad es que la globalización conlleva la disminución drástica de la capacidad normativa estatal y la emergencia de la empresa transnacional implica la "desterritorialización" de aquélla, incluso, se sitúa fuera de los campos normativos típicos, estatal o internacional, y 
crea un campo de regulación autónomo, lo que lleva consigo su emancipación de la reglamentación estatal; si bien, se trata de una "desterritorialización" relativa, puesto que siempre existe un ligamen entre el espacio territorial dotado de una cierta normatividad de origen estatal y el que organiza las relaciones laborales dentro de la empresa (Baylos Grau, 2005: 105-016).

Lo cierto es que se necesita la fijación de unos suelos laborales (homogeneizadores de los estándares de trabajo) que deben ser respetados internacionalmente, si bien, atendiendo a las diferenciadas realidades nacionales; por ejemplo, con carácter regional, la presentación del pilar europeo de derechos sociales, en cuyo desarrollo se vincula la propuesta de Directiva relativa a unas condiciones laborales transparentes y previsibles en la Unión Europea, la propuesta de Recomendación relativa al acceso a la protección social para los trabajadores por cuenta ajena y los trabajadores por cuenta propia o la propuesta de crear una Autoridad Laboral Europea. O bien, con referencia a la OIT, sus estándares internacionales sociales en torno al "trabajo decente". Recientemente, la Declaración de Naciones Unidas sobre la Agenda 2030 sobre Trabajo decente y Desarrollo Sostenible, que insta a los Estados a que se abstengan de promulgar y aplicar unilateralmente medidas económicas, financieras o comerciales que no sean compatibles con el derecho internacional y la Carta de las Naciones Unidas (Fita Ortega y Nahas, 2019: 1027-1030). Sin duda, la regulación debe tener un alcance internacional unificador y una buena vía para aprobar una reglamentación común mundial podría ser a través de un Convenio o Recomendación de la OIT. En el ámbito regional europeo, como se ha indicado, lo propio es la aprobación de una Directiva específica de "condiciones laborales justas en las plataformas digitales", es decir, una nueva regulación protectora del trabajo atípico de plataformas que también se justifica por la necesidad de garantizar que las empresas puedan competir en el libre mercado en condiciones de igualdad (Mella Méndez, 2019: 92-93). Sin unas normas mínimas de carácter social, todo quedará a la negociación, y el éxito dependerá de la fuerza de los interlocutores sociales y de sus instituciones representativas, de manera que la pérdida del garantismo jurídico-social se traduce en una regulación laboral (derecho del trabajo) que renuncia al equilibrio de intereses que está en su base genética (Moreno Vida, 2019: 259).

La "deslocalización" del tejido productivo que lleva aparejada la digitalización se ha utilizado por el empleador con el objetivo principal de aumentar la competitividad empresarial, lo que provoca el adelgazamiento de los derechos laborales y el desmantelamiento del principio de estabilidad en el empleo y la imparable liberalización del mercado de trabajo (Rodríguez Rodríguez, 2018: 212-214). Y estos son los retos más significativos para la regulación de los trabajos existentes en los procesos productivos de plataformas. Se precisa una visibilidad de conjunto, por ello es muy importante marcar bien los trazos delimitadores: una primera línea se corresponde con la norma imperativa y, en perpendicular, la concertación social, con protagonismo de los Estados, de las organizaciones internacionales y de los interlocutores sociales y económicos en ambos niveles. Si esto no se hace irán entrando en el ámbito de la autorregulación otros sujetos menos legitimados con sus propias normas. Los códigos de conducta y las políticas de responsabilidad social empresarial, sobre todo estas últimas, están constituyendo un verdadero cauce alternativo para la aplicación de los estándares internacionales de protección social y están contribuyendo al desarrollo de estructuras sindicales en el plano transnacional (redes sindicales), y por tanto, a la progresiva consolidación de un sindicalismo internacional en sentido 
propio (Rodríguez Escanciano, 2009: 101). En el ámbito nacional, el sindicato debe ganar un espacio cada vez más vinculado a las profesiones, siguiendo al trabajador a lo largo de su carrera, y no solo en el lugar de trabajo, porque estamos ante un nuevo sistema de relaciones industriales que ve su baricentro negociador en el nivel de empresa, siendo concebible que la negociación individual se convierta en la herramienta preferida para gestionar las relaciones de trabajo y se puede adivinar que la estructura de la negociación colectiva caracterizada hasta el presente por la primacía de los convenios sectoriales, no será el ámbito más adecuado para disciplinar las necesidades del trabajador y de la empresa (González-Posada Martínez, 2018: 25-27). Sin embargo, el salto del ámbito empresarial al sectorial sería lo más conveniente y determinante para homogeneizar las condiciones de trabajo en todas las cadenas de producción de una misma rama de actividad (Correa Carrasco, 2019: 51-52). No es esto lo que está sucediendo, sino que la falta de regulación se pretende salvar con una más que insuficiente creación de instrumentos de regulación y control de las condiciones laborales en las cadenas mundiales de producción, que sirven como soporte, incluso ideológico, de la denominada "responsabilidad social corporativa" (Sanguineti Raymond, 2017: 147-161). En otros términos, esta alternativa debe abandonarse por claramente insuficiente, primero por su elaboración al margen de los métodos propios de los sistemas democráticos de poder; segundo, derivado de lo anterior, por su falta de exigencia más allá de una estricta contractualización entre sujetos que sólo tienen la legitimación que les concede su estricto reconocimiento como firmantes particulares; en dos palabras, puro soft law.

Por otra parte, los espacios de producción de las normas laborales han cambiado. Se ha postergado al Estado-Nación como pieza central en la generación normativa (por la cesión de soberanía en áreas regionales como Europa), pero a lo que nos trae, también en el interior del Estado-Nación hay importantes "desplazamientos de la potestad normativa pública a los interlocutores sociales"; a su vez, son más frecuentes los momentos en los que esa autocontención estatal se muda en lo contrario, es decir, en prescripciones que cancelan la regulación estatal o colectiva, sobre aspectos importantes del trabajo, en lo que se conoce como "iniciativas de desregulación" (Baylos Grau, 2017: 490). En definitiva, la digitalización del mercado de trabajo no hecho nada más que empezar y las normativas nacionales deberían regular los derechos y obligaciones que amparan estas prestaciones de servicios, para no llegar a un punto de no retorno y desmembración de los derechos laborales mínimos (Rodríguez Rodríguez, 2018: 227). Aunque la normativa social que regule las condiciones de trabajo en los procesos productivos de plataformas sea transnacional, se deben abrir espacios adecuados a las legislaciones internas, en cuyo ámbito el marco regulatorio laboral-los cambios en las normas laborales- y el comportamiento de sus agentes, no están reñidos con la estabilidad legislativa y la seguridad jurídica, circunstancias que en una economía globalizada se "mira" particularmente por los inversores. En este sentido, lo ideal sería que la legislación laboral fuera estable y consensuada, no ya entre agentes económicos y sociales, sino también entre las fuerzas políticas. Las dos cosas están relacionadas porque "si la legislación es consensuada es más fácil que sea estable" (García-Perrote, 2019: 471). Y aquí el fenómeno de la concertación y del diálogo social tripartito es una buena forma de integración entre los dos grandes poderes operantes en el marco del sistema de relaciones laborales, el poder normativo del Estado y el poder jurídicosocial de la autonomía colectiva. Se trata de un "intercambio político" donde las grandes organizaciones de intereses intervienen en el proceso de adopción de decisiones 
de gobierno con un coste; igual para el sindicato, a quien también le entraña el coste potencial sobre su propia identidad colectiva, pues provoca relaciones de tensión con los miembros de la base, así como pérdida de influencia sobre los mismos e incluso pérdida de afiliación (Moreno Vida, 2019: 249). En más de una ocasión la Comisión y el Parlamento europeos han lanzado mensajes a los Estados miembros para que sean estos quienes protagonicen esa regulación ante las limitadas competencias de la Unión en materia laboral. Ahora bien, cualquier marco regulatorio debe contar con los agentes sociales, que no pueden quedar al margen de los debates.

Hasta ahora está siendo determinante el papel del regulador judicial para delimitar las fronteras de la laboralidad y la no laboralidad (muy pegado a relatos de elaboración de "indicios" de la ajenidad y de la dependencia), pero previamente es decisivo el papel del legislador (Casas Baamonde, 2015: 718). Parece evidente que las cosas no deben dejarse como están, y los jueces no pueden ir decidiendo caso por caso si existe un contrato de trabajo entre los prestadores de servicios con las plataformas digitales y la plataforma o si se trata de autoempleo. Esta fórmula no es adecuada para una solución universal de la situación de debilidad en las condiciones de trabajo que sufren algunos de los prestadores de servicios con las plataformas digitales, pues provoca inseguridad jurídica e, incluso, ventajas competitivas de unas plataformas frente a otras, en función de que los jueces califiquen a esos prestadores como trabajadores o como autónomos, aunque su forma de prestar servicios y su potencial de mercado sea en esencia similar (Rodríguez Fernández, 2019: 83-84).

\section{Propuesta: una gobernanza reguladora participada por el diálogo social}

Los instrumentos que han de utilizar los Estados no son otros que las normas, "un conjunto de normas mínimas" sobre el aseguramiento de los niveles mínimos de salarios, el acceso a la formación y la promoción, y la protección social. La inserción en los ordenamientos laborales de estas formas de trabajo atípicas, su cobertura por las legislaciones laborales, su "tipicidad", en otras palabras, es imprescindible para que no se conviertan en empleo precario y garanticen a los trabajadores un trabajo digno. Ningún país europeo ha acogido un modelo de flexibilización no gobernada por el Estado, por la ley laboral, y los interlocutores sociales (Casas Baamonde, 2015: 712). En el ámbito interno de los países miembros de la Unión Europea, por ejemplo en España, se puede observar como "la figura preponderante" en los procesos de concertación social es la acción estatal, que hegemoniza los procesos regulativos consensuados con los agentes sociales. Y en esta conexión que se está buscando con lo colectivo, se puede constatar que otra seña de identidad la constituye el papel siempre subsidiario que en estos procesos ocupa el sistema de negociación colectiva autónomamente considerado (Baylos Grau, 2002: 204-205). Ante un mercado de trabajo online desregulado, corresponde al Derecho Social crear y mantener el necesario equilibrio entre Economía (Digital) de Mercado y Política, que debe ser orientado de forma adecuada y dialógicamente, esto es, "bajo el principio del Diálogo Social” (Molina Navarrete, 2017: 421-422). Los propios jueces de Luxemburgo atribuyeron al diálogo social la función de sustituto del Parlamento europeo en el proceso de toma de decisiones legislativas porque eso sirve para democratizar la vida de la Unión (Veneziani, 2011: 258). Aunque sin apremio alguno y con cautelas, el Parlamento ha alentado a la Comisión a regular las nuevas formas de empleo en colaboración con los interlocutores sociales "cuando proceda", 
así, una vez resuelta la calificación de los conductores como trabajadores de Uber, implícitamente considera el Parlamento Europeo que el instrumento adecuado para la regulación de estas nuevas formas de empleo habrá de ser una directiva fruto del diálogo social, pues su propuesta toma ejemplo de las Directivas "atípicas" (véanse las traídas por Casas Baamonde, 2017: 875-876).

La promoción del diálogo social por la Comisión Europea forma parte de un largo proceso institucionalizado con claros "rasgos corporativos", porque los agentes sociales han alcanzado en la Unión cuotas importantes de participación política y se han convertido en verdaderos co-legisladores. La intendencia de estos procedimientos reguladores debe delimitar a los intervinientes y debe construirse dando entrada al diálogo social para que exista una buena gobernanza de las relaciones de trabajo en las economías digitales (empleo el plural dado que existen economías de plataformas en todos los sectores productivos con diverso alcance). La intervención de los interlocutores sociales convierte a la negociación colectiva en un procedimiento o modo de producción de normas laborales que favorece la participación activa de los ciudadanos. Con ello, a las organizaciones empresariales y sindicales, junto a los poderes públicos, se les atribuye el desempeño de un papel democrático. El diálogo social institucional es un medio de consulta y participación de los interlocutores sociales y una fórmula de cooperación tripartita, que está presente de modo fundamental en la OIT desde su nacimiento y también en el ámbito de la Unión Europea. El diálogo social -con mayor o menor grado de institucionalización- puede cumplir un papel importante en la gobernanza de las relaciones de trabajo, a través de un modelo de gestión del poder en el ámbito supranacional y en los distintos Estados. En conclusión, es un "instrumento de gobernanza muy flexible" (Moreno Vida, 2019: 269-271).

El soft law debe perder peso, solo nos vale un derecho sólido que permita mecanismos de coercibilidad. Y por aquí deben aventurarse las distintas actuaciones normativas, en el convencimiento de que se requiere una intervención reguladora de los procesos productivos en las disruptivas economías de plataformas. La experiencia de la negociación institucionalizada europea puede ser un punto de encuentro donde los interlocutores sociales europeos negocien condiciones de trabajo erga omnes gracias a la promoción del diálogo social por las instituciones comunitarias. ¿Realmente el aleph de la collaborative economy está tan escondido y tan bien camuflado que se hace inaccesible para las leyes existentes y para las que están por llegar? No lo creo; por ejemplo, mediante una Directiva se pueden regular los derechos y las obligaciones de los trabajadores en el trabajo digital. Ahora bien, debe ser a través de una Directiva consensuada donde se recojan los derechos individuales y colectivos básicos de este trabajo atípico. Es más, también pueden desarrollarse por medio de los instrumentos normativos de la OIT, que debe aprovechar el amplio espacio que en su seno ocupa el diálogo social tripartito para crear un Convenio sobre el trabajo decente en las plataformas digitales, que tenga cabida en su propuesta de Garantía Laboral Universal. Por tanto, esta "nueva regulación" no podrá hacerse al margen del diálogo social. Del mismo modo, se precisa la apertura de un proceso regulador consensuado entre la acción estatal y los interlocutores sociales sobre aspectos como el empleo de los parámetros tradicionales ante los nuevos desafíos jurídicos (la necesidad del mantenimiento de un derecho garantista de la persona del trabajador) y los derechos colectivos de los trabajadores en la economía de plataformas.

$\mathrm{Y}$ el marco regulador puede ayudarse directamente por los interlocutores sociales, en forma de diálogo social o por propia iniciativa, de la forma que se hizo tras la 
Convocatoria del Sindicato de Trabajadores Metalúrgicos de Alemania (IG Metall), que dio lugar al "Frankfurt Paper on Platform-Based Work. Proposals for platform operators, clients, policy makers, workers and worker Organizations", firmado por distintos sindicatos de Copenhague, Frankfurt, Seattle, Estocolmo, Viena y Washington, el 6 de diciembre de 2016, declaración conjunta donde se puede leer que: "En el contexto de la globalización, digitalización, flexibilización del trabajo, la creciente desigualdad de ingresos dentro de los países y la creciente polarización políticas en Europa y Estados Unidos, el trabajo justo socialmente sostenible y la participación real de los trabajadores en la configuración de las condiciones de trabajo, son más importantes que nunca. Esto es tan cierto en las plataformas digitales como en la fabricación industrial y el trabajo en oficina... Contra el riesgo del feudalismo digital, los operadores de plataforma, los trabajadores, las organizaciones de trabajadores, los clientes, los investigadores y los reguladores deben trabajar juntos para llevar la democracia a estos nuevos lugares de trabajo digital".

\section{Bibliografía}

Alemán Páez, F. (2017): "El derecho a la desconexión digital”. Trabajo y Derecho, 30: 1-20. Baylos Grau, A. (1999). "Globalización y Derecho del Trabajo: Realidad y Proyecto". Cuadernos de Relaciones Laborales. 15: 19-49.

Baylos Grau, A. (2002): "Diálogo social y negociación colectiva: una narración”, Revista de Derecho Social. 17: 203-226.

Baylos Grau, A. (2005). "Códigos de conducta y acuerdos-marco de empresas globales: apuntes sobre su exigibilidad jurídica”. Lan Harremanak. 12: 103-138.

Baylos Grau, A. (2017): "El futuro de las normas del trabajo que queremos". En Conferencia Nacional Tripartita. El futuro del trabajo que queremos. Iniciativa del Centenario de la OIT (1919-2019), Volumen II (pp. 487-501). Madrid: OIT y Ministerio de Empleo y Seguridad Social.

Baylos Grau, A. (2019). “Crisis y reconfiguración de la autonomía colectiva en el futuro del trabajo". En El futuro del trabajo: cien años de la OIT. XXIX Congreso Anual de la Asociación Española de Derecho del Trabajo y de la Seguridad Social (pp 309-338). Madrid: MTMSS.

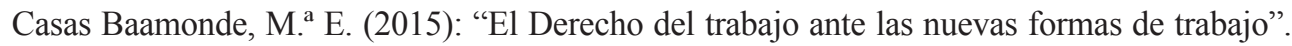
Derecho de las Relaciones Laborales, 7: 709-719.

Casas Baamonde, M. ${ }^{a}$ E. (2017): "Precariedad del trabajo y formas atípicas de empleo, viejas y nuevas. ¿Hacia un trabajo digno". Derecho de las Relaciones Laborales, 9: 867-880.

Castellano Burguillo, E. (2017): "Plataformas de empleo y plataformas de trabajo. Aspectos fundamentales". En M. Rodríguez-Piñero Royo y M. Hernández Bejarano (dirs.), Economía colaborativa y trabajo en plataforma: realidades y desafios (pp. 261-294). Albacete: Bomarzo.

Conferencia Nacional Tripartita. El futuro del trabajo que queremos (2017): Volumen I. Madrid: OIT y MESS.

Correa Carrasco, M. (2019): El derecho del trabajo y los retos planteados por la globalización y digitalización de la economía, Albacete: Bomarzo.

Cruz Villalón, J. (2017). “El futuro del trabajo y su gobernanza”. Temas Laborales. 137: 13-39.

Cruz Villalón, J. (2018). "El concepto de trabajador subordinado frente a las nuevas formas de empleo". Revista de Derecho Social. 83: 13-44. 
Cuadros Garrido, M. ${ }^{a}$ E. (2019): "Hacia una reinterpretación de la relación de trabajo por la disrupción de las plataformas digitales". En El futuro del trabajo: cien años de la OIT. XXIX Congreso Anual de la Asociación Española de Derecho del Trabajo y de la Seguridad Social (pp 149-167). Madrid: MTMSS.

Fita Ortega, F. y Nahas, T. C. (2019): "La necesidad de una nueva internacionalización, o supranacionalidad, para asegurar la efectividad de la gobernanza de las relaciones de trabajo". En El futuro del trabajo: cien años de la OIT. XXIX Congreso Anual de la Asociación Española de Derecho del Trabajo y de la Seguridad Social (pp 1033-1052). Madrid: MTMSS.

García Quiñones, J. C. (2018): "Economía colaborativa y Derecho del trabajo: dos realidades obligadas a entenderse en un contexto de difícil convivencia”. En Mella Méndez, L. (dir.), La revolución tecnológica y sus efectos en el mercado de trabajo: un reto del siglo XXI (pp 97-154). Madrid: Wolters Kluwer.

García-Perrote Escartín, I. (2019): "La gobernanza de las relaciones de trabajo". En El futuro del trabajo: cien años de la OIT. XXIX Congreso Anual de la Asociación Española de Derecho del Trabajo y de la Seguridad Social (pp 197-231). Madrid: MTMSS.

Garrido Pérez, E. (2017): "La representación de los trabajadores al servicio de plataformas colaborativas". Revista de Derecho Social. 80: 209-232.

González-Posada Martínez, E. (2018). "El papel del Estado y las relaciones laborales: una geometría compleja y variable”. Temas Laborales. 142: 13-31.

Instituto Cuatrecasas de Estrategia Legal en RR HH (2019): "Economía de plataformas y marco regulatorio". C. (2019). En Del Rey Guanter, S. (dir.), Economía de plataformas, Blockchain y su impacto en los Recursos Humanos y en el Marco Regulatorio de las Relaciones Laborales. Proyecto Technos (pp 125-291). Madrid: Wolters Kluwer Instituto Cuatrecasas.

Martínez Moreno, C. (2018). "El concepto de trabajador”. En M. a E. Casas Baamonde y R. Gil Alburquerque (dirs.), Derecho Social de la Unión Europea. Aplicación por el Tribunal de Justicia (pp 187-205). Madrid: Francis Lefebvre El Derecho.

Martínez Moreno, C. (2019). "La autonomía colectiva y sus medios de expresión". En El futuro del trabajo: cien años de la OIT. XXIX Congreso Anual de la Asociación Española de Derecho del Trabajo y de la Seguridad Social (pp 275-308). Madrid: MTMSS.

Mella Méndez, L. (2019). "Calificación jurídica de la relación que une a los prestadores de servicios con las plataformas digitales”. En M. ${ }^{a}$ L. Rodríguez Fernández (dir.), Plataformas digitales y mercado de trabajo (pp 91-123). Madrid: MTMSS.

Mercader Uguina, J. R. (2003): "Sistema de fuentes y globalización”, Revista Española de Derecho del Trabajo. 119: 667-690.

Mercader Uguina, J. R. (2017): El futuro del trabajo en la era de la digitalización y la robótica, Valencia: Tirant lo Blanch.

Molina Navarrete, C. (2017): "Derecho y trabajo en la era digital: ¿"Revolución industrial 4.0" o "Economía sumergida 3.0"? En Conferencia Nacional Tripartita. El futuro del trabajo que queremos. Iniciativa del Centenario de la OIT (1919-2019), Volumen II (pp. 403-423). Madrid: OIT y MTMSS.

Monereo Pérez, J. L. (2017): La metamorfosis del Derecho del Trabajo, Albacete: Bomarzo.

Monereo Pérez, J. L. (2019): "Refundar el ordenamiento laboral para juridificar plenamente el principio de justicia social y el trabajo decente", Revista Jurídica de los Derechos Sociales. Lex Social. Volumen 9 (1): 220-294.

Moreno Vida, M. ${ }^{\text {a }}$ N. (2019). "La gobernanza de las relaciones de trabajo". En El futuro del trabajo: cien años de la OIT. XXIX Congreso Anual de la Asociación Española de Derecho del Trabajo y de la Seguridad Social (pp 233-272). Madrid: MTMSS. 
Ramos Quintana, M. (2018): “Un soporte jurídico para el trabajo digital, ¿qué trabajo? Trabajo y Derecho, 47: 1-5.

Rodríguez Escanciano, S. (2009): "La necesaria adaptación de la estrategia sindical a las transformaciones actuales de las organizaciones empresariales: algunas cuestiones a considerar", Revista Universitaria de Ciencias del Trabajo, 10: 95-120.

Rodríguez Fernández, M. ${ }^{a}$ L. (2017). "Plataformas, microworkers y otros desafíos del trabajo en la era digital”. En L. Mora Cabello de Alba, L. y M. ${ }^{a}$ L. Rodríguez Fernández (coords.), El futuro del trabajo que queremos (pp. 95-113). Albacete: Bomarzo.

Rodríguez Fernández, M. ${ }^{a}$ L. (2019). "Calificación jurídica de la relación que une a los prestadores de servicios con las plataformas digitales”. En M. ${ }^{a}$ L. Rodríguez Fernández (dir.), Plataformas digitales y mercado de trabajo (pp 57-89). Madrid: MTMSS.

Rodríguez Rodríguez, E. (2018): “La prestación de servicios a través de plataformas digitales: cambios en la organización del trabajo y en las relaciones laborales". En J. M. a Miranda Boto (dir.), El Derecho del Trabajo español ante el Tribunal de Justicia: problemas y soluciones (pp. 211-235). Madrid: Cinca.

Rodríguez-Piñero Royo, M. (2017). "La agenda reguladora de la economía colaborativa: aspectos laborales y de seguridad social”. Temas Laborales. 138: 125-161.

Rodríguez-Piñero Royo, M. (2017): "El jurista del trabajo frente a la economía colaborativa". En M. Rodríguez-Piñero Royo y M. Hernández Bejarano (dirs.), Economía colaborativa y trabajo en plataforma: realidades y desafios (pp. 187-221). Albacete: Bomarzo.

Rojas Rosco, R. (2018): "Hacia un nuevo estatuto jurídico del trabajador de las plataformas digitales”. En F. Pérez de los Cobos (dir.), El trabajo en plataformas digitales. Análisis sobre su situación jurídica y regulación futura (pp. 119-136). Madrid: Wolters Kluwer.

San Martín Mazzucconi, C. (2017): “Generalización tecnológica: efectos sobre las condiciones de trabajo y empleo". En Conferencia Nacional Tripartita. El futuro del trabajo que queremos. Iniciativa del Centenario de la OIT (1919-2019), Volumen II (pp. 297-309). Madrid: OIT y MESS.

Sanguineti Raymond, W. (2017): Redes empresariales y Derecho del Trabajo, Granada: Comares.

Serrano Olivares, R. (2017): "Nuevas formas de organización empresarial: economía colaborativa -o mejor, economía digital a demanda-, trabajo 3.0 y laboralidad". En M. Rodríguez-Piñero Royo y M. Hernández Bejarano (dirs.), Economía colaborativa y trabajo en plataforma: realidades y desafios (pp. 19-49). Albacete: Bomarzo.

Todolí Signes, A. (2017): El trabajo en la era de la economía colaborativa, Valencia: Tirant lo Blanch.

Trillo Párraga, F. (2016): "Economía digitalizada y relaciones de trabajo", Revista de Derecho Social. 76: 59-82.

Trillo Párraga, F. (2017): “Trabajo decente y economía digitalizada”. En L. Mora Cabello de Alba, L. y M. ${ }^{a}$ L. Rodríguez Fernández (coords.), El futuro del trabajo que queremos (pp. 71-93). Albacete: Bomarzo.

Valdés Dal-Ré, F. (2017): "Prólogo". En Monsalve Cuéllar, M. ${ }^{a}$ E. (coord.), El futuro del trabajo. Análisis jurídico y socioeconómico (pp. 7-13). Cuenca: Alderabán.

Vega Ruiz, M. ${ }^{a}$ L. (2019). "Trabajo, la relación de trabajo y Derecho del trabajo: ¿crisis o renacimiento?". En El futuro del trabajo: cien años de la OIT. XXIX Congreso Anual de la Asociación Española de Derecho del Trabajo y de la Seguridad Social (pp 81-99). Madrid: MTMSS.

Veneziani, B. (2011): "L'art. 152 del Trattato di Lisbona: Quale futuro per i social partners?", Revista giuridica del lavoro e della providenza sociale, Vol. 62-1: 243-265. 